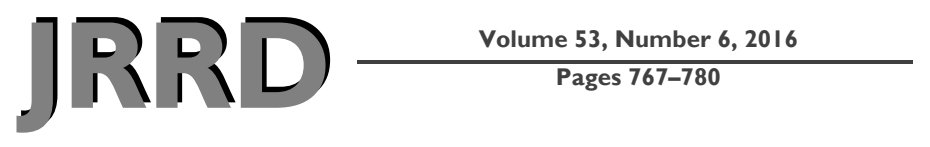

\title{
The Veterans Health Administration's traumatic brain injury screen and evaluation: Practice patterns
}

\begin{abstract}
Heather G. Belanger, PhD; ${ }^{1-2 *}$ Gail Powell-Cope, PhD, ARNP, FAAN; ${ }^{1}$ Andrea M. Spehar, DVM, MPH, JD,

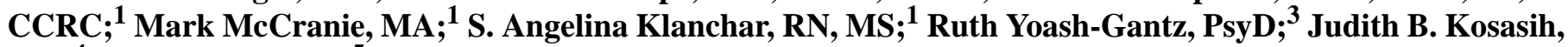
MD; ${ }^{4}$ Joel Scholten, $\mathbf{M D}^{\mathbf{5}}$

${ }^{1}$ Center of Innovation on Disability and Rehabilitation Research, Health Services Research \& Development, James A. Haley Veterans' Hospital, Tampa, FL; ${ }^{2}$ Department of Mental Health and Behavioral Sciences, James A. Haley Veterans' Hospital, Tampa, FL; Department of Psychiatry and Behavioral Neurosciences, University of South Florida, Tampa, FL; and Defense and Veterans Brain Injury Center, Silver Spring, MD; ${ }^{3}$ Department of Mental Health and Behavioral Sciences, W. G. (Bill) Hefner Department of Veterans Affairs Medical Center (VAMC), Salisbury, NC; and Department of Psychiatry and Behavioral Medicine, Wake Forest School of Medicine, Winston-Salem, NC; ${ }^{4}$ Department of Physical Medicine and Rehabilitation, Clement J. Zablocki VAMC, Milwaukee, WI; and Department of Physical Medicine and Rehabilitation, Medical College of Wisconsin, Milwaukee, WI; ${ }^{5}$ Department of Physical Medicine and Rehabilitation, Washington DC VAMC, Washington, DC
\end{abstract}

\begin{abstract}
The goals of this study were to describe clinical practice patterns associated with the Veterans Health Administration's (VHA's) Comprehensive Traumatic Brain Injury Evaluation (CTBIE) and determine whether practice patterns vary by patient, provider, or facility characteristics. Veterans $(N=$ 614) who had initial healthcare visits between 2008 and 2011 and who had previously completed the VHA's traumatic brain injury (TBI) screen and subsequent CTBIE were drawn from a national database. Participants were primarily male (95\%) with a mean age of $29.8 \mathrm{yr}$ (standard deviation $=8$ ). Chart reviews were conducted on a random sample of charts with completed CTBIEs from 21 sites. Using a cross-sectional design, patientand facility-specific variables were investigated as potential predictors of practice variation. During the study period, 79\% of patients in this national sample were screened within $1 \mathrm{~d}$ of their initial healthcare visit and $65 \%$ were evaluated via CTBIE within $30 \mathrm{~d}$ of screening. Provider and participant characteristics were generally not associated with timeliness. The CTBIE was completed by individuals versus teams at comparable rates. Much of what occurred during the evaluation, beyond TBI-specific procedures, were medical assessments, such as review of medications and other substances.
\end{abstract}

Key words: brain injuries, concussion, Department of Veterans Affairs, diagnosis, mass screening, practice patterns, practice variation, TBI, traumatic brain injury evaluation, traumatic brain injury screening.

\footnotetext{
Abbreviations: CTBIE $=$ Comprehensive Traumatic Brain Injury Evaluation, DES = data entry system, IRB = institutional review board, NSI $=$ Neurobehavioral Symptom Inventory, $\mathrm{OEF}=$ Operation Enduring Freedom, OIF = Operation Iraqi Freedom, OND = Operation New Dawn, RDC = Research and Development Committee, TBI = traumatic brain injury, $\mathrm{VA}=$ Department of Veterans Affairs, VAMC $=$ Department of Veterans Affairs Medical Center, VHA $=$ Veterans Health Administration.

*Address all correspondence to Heather G. Belanger, PhD; James A. Haley Veterans' Hospital, Physical Medicine and Rehabilitation-117, 13000 Bruce B. Downs Blvd, Tampa, FL 33612; 813-972-2000, ext 4757; fax: 813-903-4814.

Email: Heather.Belanger@va.gov http://dx.doi.org/10.1682/JRRD.2015.09.0187
} 


\section{INTRODUCTION}

Practice variation occurs when patients with similar diagnoses receive different levels of care depending on when, where, and by whom they are treated. There is ample evidence that practice variation occurs in medicine [1-2], even when clear clinical practice guidelines exist [3], and that such variations produce uneven health outcomes and increase costs [4-6]. Furthermore, variations often cannot be explained by illness severity or patient factors and result in idiosyncratic, unscientific clinical practice [6].

Reasons underlying clinical practice variation are numerous. Some factors explaining the lack of consistent implementation of practice guidelines may include the complexity of the clinical guidelines in question (i.e., their ease of use), providers' beliefs concerning the appropriateness or validity of the guidelines, and clinician-specific and environment-specific barriers. Some theorists contend that practice variation is related to provider differences in action "thresholds," or the tendency to decide to act versus not act [7-8]. This threshold may be affected by diagnostic uncertainty - that is, the greater the uncertainty, the more variable the thresholds may be across providers.

The diagnosis of mild traumatic brain injury (TBI) is fraught with diagnostic uncertainty, particularly when the patient presents in the postacute setting. Mild TBI is a historical diagnosis, requiring knowledge of acute injury parameters for its determination (e.g., duration of posttraumatic confusion and loss of consciousness). Frequently, the injury event is not witnessed or documented by medical personnel. Also, any period of disturbed consciousness may resolve before it can be assessed and documented by medical personnel. This is particularly true in a combat setting where life or death may be at stake, so care for non-life-threatening injuries may be delayed. Thus, in a healthcare system such as the Veterans Health Administration (VHA), when providers are asked to make a mild-TBI diagnosis well after the injury event, and often based on self-report remote history, there can be much uncertainty. In turn, such diagnostic uncertainty could presumably lead to practice variations.

Because of the increase in polytrauma injuries and TBI in returning Active Duty personnel and Veterans of Operation Iraqi Freedom (OIF), Operation Enduring Freedom (OEF), and Operation New Dawn (OND), the VHA developed a comprehensive and integrated system of care to treat these returning Veterans and servicemembers. The Polytrauma System of Care has tiered levels of care with four overall components, from highly specialized TBI acute care and rehabilitation services to tertiary centers that coordinate access to VHA and non-VHA services to meet the needs of patients and their families [9-10].

Initially, screening for polytrauma injuries and TBI in Active Duty personnel who are deployed to Iraq and Afghanistan is conducted in theater at a military medical center, garrison, or treatment facility using one of several tools [11-12]. At all VHA facilities, staff use a series of postdeployment clinical reminders or population-based screens for various deployment-related conditions. When an OIF/OEF/OND Veteran or Active Duty member first enters a VHA facility to receive healthcare, a prompt automatically populates the new electronic medical record, informing staff which screens are required. The TBI Clinical Reminder consists of four screening questions: "(1) During any of your OEF/OIF/OND deployment(s), did you experience any of the following events? (blast or explosion, vehicular accident/crash, fragment wound or bullet wound above the shoulders, fall, blow to head, other injury to head); (2) Did you have any of these symptoms immediately afterwards? (losing consciousness/knocked out, being dazed, confused or 'seeing stars,' not remembering the event, concussion, head injury); (3) Did any of the following problems begin or get worse afterwards? (memory problems or lapses, balance problems or dizziness, sensitivity to bright light, irritability, headaches, sleep problems); and (4) In the past week, have you had any of the symptoms from section 3?" [13]. A positive response to all four questions constitutes a positive TBI screen. Rates of positive TBI screens in Department of Veterans Affairs (VA) settings average about 20 percent [14]. Recent analysis of TBI diagnosis rates after deployment suggests possible delays in diagnosis, signaling potential gaps in screening or variations in screening and follow-up practices [15].

A positive TBI Clinical Reminder Screen triggers a Comprehensive TBI Evaluation (CTBIE), which consists of a detailed assessment of blast exposures and injurious events, a targeted review of symptoms, a physical examination, a definitive diagnoses or other explanation for symptoms, and a treatment plan. The CTBIE is designed to determine whether the patient sustained a TBI and then guide development of an appropriate plan of care regardless of whether a TBI was sustained. Embedded within the computer-based CTBIE template that populates a 
report in the electronic medical chart is the Neurobehavioral Symptom Inventory (NSI) [16], a 22-item postconcussive symptom questionnaire. Experts in TBI developed a VHA TBI treatment algorithm around the 22 symptoms of the NSI to provide the clinician with referral, assessment, and treatment considerations when developing a plan of care [17]. In an observational study using VHA administrative data for October 2007 through June 2010, 55,070 Veterans with positive TBI screens completed CTBIEs. Of these, all participants reported a minimum of one or more postconcussion symptoms on the NSI; the majority (over 75\%) of these symptoms were rated at the moderate to very severe level of severity, but symptoms were rated as more severe for those with a TBI diagnosis compared to those without [18]. The psychometric properties of the TBI screen and CTBIE have been investigated [19-21]. Generally, the TBI screen was found to have good internal consistency, variable test-retest reliability, and variable validity [21].

In addition, the level of adherence to the screening and evaluation process is monitored by the VHA, yet the effectiveness of this process is largely unknown. Three studies examined factors associated with getting screened for TBI in the VA [22-24]. While there were some different findings, likely based on the selected samples, all three studies found that being recently separated from the military was associated with a greater likelihood of being screened. Two of the three studies also found that older age, having a service-connection rating [22,24], and being male [22-23] were associated with a greater likelihood of being screened. In contrast, there were conflicting findings related to psychiatric status and facility type, which suggest that at least some predictors may be sample specific.

Variations in practice may exist based on the level of polytrauma care, given varying levels in provider training and experience and resources, as well as the aforementioned diagnostic uncertainty and coexisting comorbidities. Given the amount of resources used by the VHA to care for Veterans undergoing screening, improving the quality of TBI care is a high priority. Identifying gaps between guidelines and clinical practice has been helpful in other areas of healthcare by highlighting factors associated with poor compliance with recommendations and by increasing compliance with them [25-26]. Improved adherence to treatment guidelines is typically associated with better outcomes across a variety of diseases and health conditions [27-28].
The primary purpose of the current study was to describe and characterize the TBI screen and CTBIE processes across facilities and to determine whether patient, provider, or facility characteristics (i.e., practice variation) are associated with timeliness. Secondary purposes were to investigate the extent to which the TBI screen and CTBIE processes led to increased identification and follow-up of problem conditions and to examine the rate of symptom-specific evaluation and follow-up referral following the CTBIE.

\section{METHODS}

\section{Participants}

The protocol was approved by the VA Central Institutional Review Board (IRB) and by each individual site's local Research and Development Committee (RDC). Twenty-one VHA sites, randomly selected within each tier of the polytrauma system and geographic region, were chosen to participate in this study. Potential participants were identified through the VHA's Patient Care Services database of OIF/OEF/OND Veterans. Of those patients screening positive on the TBI screen from each site, 50 were randomly selected from each of the 21 sites $(n=1,050)$. Of these patients, only those with documented CTBIEs and initial healthcare visits between October 1, 2008, and March 31, 2011, were selected for further analysis. This time frame was used because VHA guidance about clinical management of Veterans screening positive was issued in April 2007; we presumed that using this time frame allowed adequate time for sites to incorporate the guidance into practice. Potential participants with a positive screen but no documented CTBIE $(n=164)$ were excluded, providing a total sample of 614 participants who had completed the VHA TBI Clinical Reminder Screen and CTBIE, thus meeting inclusion criteria. (The remaining 272 potential participants were excluded because they had an initial postdeployment healthcare visit outside the specified window.) Those included in analyses were more likely to be married $\left(\chi^{2}=\right.$ $6.44, p<0.04)$ and also more likely to be screened within $1 \mathrm{~d}\left(\chi^{2}=5.7, p<0.02\right)$, as compared with those who were excluded. A combination of electronic medical record chart reviews and national VHA databases was used to gather demographic and other data on participants. 


\section{Variables and Measures}

Chart reviews were conducted on the sample to extract data. The specialty and clinic location of the TBI screen were identified. In addition, other information was collected, including key assessments completed during the CTBIE, relevant dates, problem lists, referrals, services rendered during or resulting from the CTBIE, and the discipline of the specialist completing the screen and CTBIE.

The NSI [16], administered by clinicians during the CTBIE was also extracted. The NSI is a 22 -item selfreport questionnaire to assess cognitive, affective, somatic, and vestibular symptoms. Respondents rate how much a symptom has bothered them since their injury on a scale ranging from 0 to 4 , with higher scores indicating greater symptom severity. The NSI total score is the most commonly used index; it ranges from 0 to 88 . From the NSI, symptom cluster groups were created to examine CTBIE-specific practice patterns associated with three specific symptom clusters. The following groupings, created a priori based on the VA's TBI treatment/management algorithm [17], were used to examine practice patterns associated with symptom endorsement on the NSI. Symptom clusters included:

1. Affective: Those who endorsed at least one of the four following symptoms: feeling anxious/tense, feeling depressed/sad, feeling irritable/easily annoyed, or poor frustration tolerance/overwhelmed.

2. Hearing: Those who endorsed at least one of the two following symptoms: hearing difficulty or sensitivity to noise.

3. Cognitive: Those who endorsed at least one of the five following symptoms: forgetfulness/can't remember things, poor concentration/easily distracted, difficulty making decisions, or slowed thinking/difficulty getting organized/can't finish things.

The other symptoms from the NSI (i.e., physical symptoms) were not analyzed because the a priori intent was to do a focused review on certain symptom clusters (not all) given the time resource intensity of chart reviews. These clusters were chosen because of the frequency of these particular symptoms in our population [29-30] and our interest in service-specific resource allocation for nonrehabilitation service lines (i.e., mental health and audiology). All CTBIE-related care events that occurred during and/or as a result of the CTBIE, such as symptom-specific referrals and treatments, were extracted and linked to the symptom groups as specified in the VA practice algorithms. Charts of patients who endorsed affective symptoms were assessed for subsequent mental health care by a mental health specialist (i.e., neuropsychologist, psychiatrist, or psychologist) or in a mental health clinic. Similarly, hearing-related treatments were documented when the patient was seen either by an audiologist or speech pathologist or in a speech or audiology clinic. Both these specialties were included because they were frequently impossible to differentiate (e.g., patient seen in a speech-audiology clinic). Cognitive-related care was documented when the patient was seen by a neuropsychologist, neurologist, or speech pathologist/therapist for these symptoms as a result of the CTBIE. It is important to note that the specific target of treatment was not coded and is unknown. So, for example, if a participant endorsed cognitive symptoms and was sent to a neuropsychologist, an inference was made that this represented a "cognitive referral," but the actual treatments rendered are unknown (i.e., it could be that the neuropsychologist treated mental health symptoms, not cognitive ones, or treated mental health symptoms to improve cognition).

Dependent variables of timeliness and quality of care were operationalized for each symptom group by a panel of experts using guidance issued from the VA Physical Medicine and Rehabilitation Service in 2012 [13]. This directive provided VHA clinicians and leadership with specific measures, timelines, and accountability for screening and evaluation of TBI in postdeployed patients. For example, an initial TBI screen should occur at the initial VHA healthcare visit. A positive screen results in a referral for a CTBIE, which must be provided by a specialized team with the requisite specialists, such as a physiatrist, neurologist, or neuropsychiatrist. A patient with possible TBI is to be seen for the CTBIE within $30 \mathrm{~d}$ of the initial positive screen regardless of the facility or specialty team responsible for completing the evaluation. Documentation of the efforts to schedule the CTBIE (e.g., at least two additional telephone calls within $14 \mathrm{~d}$ of the positive screen, and, if no response, mailing of a certified letter) are to be entered in the Veteran's computerized medical record. In order to document adherence to this directive and subsequent VHA directives for screening and comprehensive evaluation of TBI in OIF/OEF/ OND Veterans, a database application was developed as a tool for data extraction from the electronic medical record. 


\section{Procedures}

For charts with more than one TBI screen, the screen that was linked to the CTBIE was studied. All chart reviews were completed using a data entry system (DES) that was developed, deployed, and managed by an experienced database manager.

In an effort to reduce data redundancy and other data quality concerns, a number of data validation controls were implemented across all levels of the DES design. Key stakeholders, such as principal investigators, the project coordinator, and data entry personnel, were included in all aspects of the DES development process through both individual and study team group meetings. Data tables or domains were developed to align with the main objectives of the research study (patient master, demographics, TBI screens, CTBIE, specialist referrals and visits, specialist-related treatments, delays between the TBI screen and CTBIE, etc.), and relationships between these tables were established using a common unique identifier (primary key) that linked patient-centric records across the various domains (data entry tables). Field- or column-level constraints were applied to enforce overall data integrity by restricting allowable values within table fields/columns. Examples included setting data types (integer, text, date/time, Boolean, etc.) of table fields, requiring primary key values to be unique, setting default values for selected fields, preventing null or missing values, and restricting the range of allowable attributes (values) using field drop-down lists on data entry forms.

Some data, such as the date of the first postdeployment visit, demographics, dates for TBI screens, and referrals and evaluations, were captured via data batching from the OIF/OEF roster, VHA Support Service Center, and Patient Care Services data sets. These data were preloaded into the DES prior to the data entry process to help guide data personnel through the data entry process and provide a cross-reference to data within the electronic medical record.

Data entry forms were accessible from a selection tab at the top of the main form and allowed data entry personnel to move freely among the main form modules during the chart review process. Various logical controls or constraints were implemented during this process, including event-driven informational dialogue boxes and/ or user alerts related to data validation issues such as missing or inconsistent data entries. Form modules were coded to perform data validation checks based on pre- defined rules derived from approved protocol methodology, goals, and objectives. Additional data quality checks were conducted regularly by the database manager throughout the life cycle of the data entry process. Records with missing data and/or inconsistencies were flagged and reviewed by data entry personnel to resolve inaccuracies prior to releasing the record for final analysis.

Chart reviews were conducted by one data collector. Records were randomly selected for interrater reliability analyses with a second chart reviewer independently reviewing the same charts, blind to the first review. The overall agreement for all assessments was 93.97 percent for all but 3 of the 45 assessed clinical metrics in the 13 charts reviewed. The overall Spearman rho, which puts no restriction on square cells, was calculated to be 0.98 $(p<0.001)$. During weekly research team meetings, the data collector brought questions she had about data collection and coding to the investigators. Issues were discussed and resolutions were achieved through consensus among investigators. Decisions were documented in a code book as a reference for the data collector.

\section{Data Analysis}

Logistic regression was used to determine whether timeliness was related to patient, provider, or facility characteristics. Based on the time between the initial healthcare visit and the TBI screen and the time between the TBI screen and the CTBIE, grouping variables were created. Each participant was categorized into (1) those who were screened within $1 \mathrm{~d}$ of their initial healthcare visit (or screened via phone beforehand) $(n=488)$ or (2) those who were screened more than $1 \mathrm{~d}$ beyond their initial healthcare visit $(n=126)$. In addition, each participant was further categorized into (1) those who completed a CTBIE within $30 \mathrm{~d}$ of their TBI screen $(n=400)$ and (2) those who completed the CTBIE more than $30 \mathrm{~d}$ from their TBI screen $(n=204)$. The latter variable was missing data for 10 patients because a link between the screen and the CTBIE could not be determined. For those who did not complete the CTBIE within $30 \mathrm{~d}$, the reasons were explored via chart review, and follow-up actions by the facility were documented (e.g., calling the patient to reschedule).

\section{Patient Characteristics}

Binary logistic regression models were used to examine the time-related grouping variables as dependent measures and the following patient characteristics as 
predictors: age, education, employment status, race, marital status, military rank, and whether TBI was diagnosed by the provider during the CTBIE. All variables except age were binary (e.g., education $=$ not college educated vs at least college educated).

\section{Provider and Level of Care Characteristics}

Binary logistic regression models were run with the time-related grouping variables as dependent measures (i.e., screening done within $1 \mathrm{~d}$ or not and CTBIE done within $30 \mathrm{~d}$ or not). The following facility characteristics were entered as predictors of screening timeliness: professional discipline completing the TBI screen and facility polytrauma level of care. For timeliness of the CTBIE, the following variables were entered as predictors: polytrauma facility level and team versus individual approach to CTBIE. These variables are detailed in Table 1. It is important to note that a "team approach" was defined very broadly. The CTBIE was considered completed by a team if (1) a provider, other than the primary CTBIE provider, fully performed any portion of the initial CTBIE, even if it was prior to the date of the CTBIE itself (e.g., vitals check), or (2) the CTBIE appointment was completed by a predetermined or preassigned team. In contrast, an individual approach meant that the entire CTBIE was done independently by one provider.

Descriptive statistics were used to report documented assessments and treatments conducted during the CTBIE and to delineate the number of new problems added to a patient's "problem list" (i.e., part of the VA's electronic medical chart that lists the patient's current medical and psychiatric conditions) vis-à-vis timing of the TBI screen and CTBIE and the number of referrals made and carried out according to symptom clusters endorsed on the NSI.

\section{RESULTS}

\section{Participant Characteristics and Timeliness}

Demographic characteristics of the final sample are presented in Table 2 . The sample was primarily male $(95.3 \%)$, white $(60.4 \%)$, single (never married and divorced, 63.0\%), with service in the Army (67.4\%), and with a mean age of 29.8. The majority of individuals (57.8\%) discussed more than one injurious event during the CTBIE. Ultimately, about half the patients (58.6\%) were diagnosed with TBI by the CTBIE provider. For the 27 percent of the sample that had been screened more
Table 1.

Facility characteristics.

\begin{tabular}{|c|c|}
\hline Characteristic & $\begin{array}{l}\text { Frequency } \\
\text { or Mean }\end{array}$ \\
\hline \multicolumn{2}{|l|}{ First Healthcare Visit, No. (\%) } \\
\hline Primary Care & $351(57.2)$ \\
\hline Mental Health & $82(13.4)$ \\
\hline Specialty Clinic & $91(14.8)$ \\
\hline Emergency Room or Urgent Care & $79(12.8)$ \\
\hline Inpatient & $4(0.7)$ \\
\hline Other or Unknown & $7(1.1)$ \\
\hline \multicolumn{2}{|l|}{ Level of Care, ${ }^{*}$ No. $(\%)$} \\
\hline Polytrauma Center & $72(11.7)$ \\
\hline Polytrauma Network Site & $75(12.2)$ \\
\hline Polytrauma Support Clinical Team & $104(16.9)$ \\
\hline Polytrauma Point-of-Contact & $123(20.0)$ \\
\hline $\operatorname{Missing}^{\dagger}$ & $240(39.1)$ \\
\hline \multicolumn{2}{|l|}{ Professional Doing Screen, No. (\%) } \\
\hline Nurse & $218(35.5)$ \\
\hline Social Worker/Case Manager & $182(29.6)$ \\
\hline Physician/Dentist & $130(21.2)$ \\
\hline Other & $61(9.9)$ \\
\hline Missing & $23(3.7)$ \\
\hline \multicolumn{2}{|l|}{ Team vs Individual CTBIE, No. (\%) } \\
\hline Individual & $294(47.9)$ \\
\hline Team & $320(52.1)$ \\
\hline \multicolumn{2}{|l|}{ Professional Doing CTBIE ${ }^{*}$ No. (\%) } \\
\hline Physician & $251(85.4)$ \\
\hline Physician's Assistant & $27(9.2)$ \\
\hline Nurse Practitioner & $12(4.1)$ \\
\hline Other/Unknown & $4(1.4)$ \\
\hline NSI Completed & 607 (99) \\
\hline $\begin{array}{l}\text { Time Between First Healthcare Visit and } \\
\text { Screen (d) }{ }^{\S} \text { Mean (SD) }\end{array}$ & $28.80(99.0)$ \\
\hline $\begin{array}{l}\text { Time Between Screen and CTBIE (d), } \\
\text { Mean (SD) }\end{array}$ & $44.31(93.0)$ \\
\hline $\begin{array}{l}\text { Time Between CTBIE and Affective } \\
\text { Specialist Visit (d), Mean (SD) }\end{array}$ & $51.80(99.6)$ \\
\hline $\begin{array}{l}\text { Time Between CTBIE and Hearing } \\
\text { Specialist Visit (d), Mean (SD) }\end{array}$ & $60.50(89.1)$ \\
\hline $\begin{array}{l}\text { Time Between CTBIE and Cognitive } \\
\text { Specialist Visit (d), Mean (SD) }\end{array}$ & $83.19(124.1)$ \\
\hline $\begin{array}{l}\text { Time Between CTBIE and Headache } \\
\text { Specialist Visit (d), Mean (SD) }\end{array}$ & $74.94(103.2)$ \\
\hline \multicolumn{2}{|c|}{ 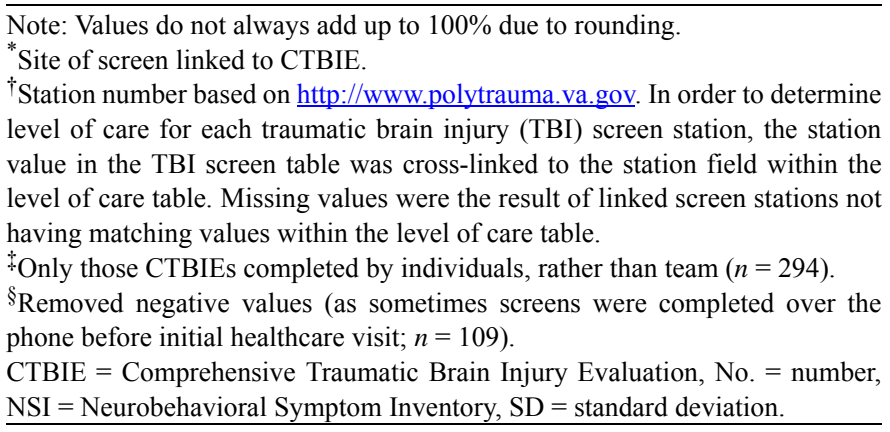 } \\
\hline
\end{tabular}


Table 2.

Demographic information $(N=614)$.

\begin{tabular}{|c|c|}
\hline Demographics & Mean or Frequency \\
\hline Age (yr), Mean (SD) & $29.8(8.0)$ \\
\hline NSI Total Score, Mean (SD) & $35.6(16.6)$ \\
\hline \multicolumn{2}{|l|}{ Sex, No. $(\%)$} \\
\hline Male & $585(95.3)$ \\
\hline Female & $29(4.7)$ \\
\hline \multicolumn{2}{|l|}{ Race/Ethnicity, No. (\%) } \\
\hline White & $371(60.4)$ \\
\hline African American & $48(7.8)$ \\
\hline Hispanic & $49(8.0)$ \\
\hline Other & $146(23.8)$ \\
\hline \multicolumn{2}{|l|}{ Marital Status, No. (\%) } \\
\hline Never Married & $364(59.3)$ \\
\hline Married/Partnered & $226(36.8)$ \\
\hline Divorced & $24(3.9)$ \\
\hline \multicolumn{2}{|l|}{ Education, No. (\%) } \\
\hline GED, High School Diploma, or Less & $530(86.2)$ \\
\hline Some College & $25(4.1)$ \\
\hline Associate's Degree & $14(2.3)$ \\
\hline Bachelor's Degree & $32(5.2)$ \\
\hline Master's Degree & $1(0.2)$ \\
\hline Unknown & $12(2.0)$ \\
\hline \multicolumn{2}{|l|}{ Employment Status, No. (\%) } \\
\hline Unemployed & $328(53.4)$ \\
\hline Employed (either full- or part-time) & $286(46.6)$ \\
\hline \multicolumn{2}{|l|}{ Branch of Service, No. $(\%)$} \\
\hline Army & $414(67.4)$ \\
\hline Navy & $48(7.8)$ \\
\hline Air Force & $18(2.9)$ \\
\hline Marine Corps & $133(21.7)$ \\
\hline Coast Guard & $1(0.2)$ \\
\hline \multicolumn{2}{|l|}{ Rank, No. (\%) } \\
\hline Enlisted & $594(96.7)$ \\
\hline Officer & $15(2.4)$ \\
\hline Warrant & $5(0.8)$ \\
\hline \multirow{2}{*}{\multicolumn{2}{|c|}{$\begin{array}{l}\text { No. Potential TBI Events Discussed } \\
\text { During CTBIE, No. }(\%)\end{array}$}} \\
\hline & \\
\hline 0 & $24(3.9)$ \\
\hline 1 & $191(31.1)$ \\
\hline$>1$ & $355(57.8)$ \\
\hline Unclear & $44(7.2)$ \\
\hline \multicolumn{2}{|l|}{$\begin{array}{l}\text { TBI Diagnosed by Provider During } \\
\text { CTBIE, No. }(\%)\end{array}$} \\
\hline Not Answered & $1(0.2)$ \\
\hline 0 & $253(41.2)$ \\
\hline$\geq 1$ & $360(58.6)$ \\
\hline$>1 \mathrm{No} /$ Unclear & $300(83)$ \\
\hline$>1$ Yes & $60(17)$ \\
\hline
\end{tabular}

Note: Employment reflects current status. Military branch and rank responses reflect time of deployment. Values do not always add up to $100 \%$ due to rounding. CTBIE = Comprehensive Traumatic Brain Injury Evaluation, GED = general equivalency diploma, No. $=$ number, NSI $=$ Neurobehavioral Symptom Inventory, $\mathrm{SD}=$ standard deviation, $\mathrm{TBI}=$ traumatic brain injury. than once, we focused on the screen that was linked to the CTBIE (only 16 cases, or $3 \%$, had more than one CTBIE; in these cases, we selected the first screenCTBIE pairing). On average, $28.8 \mathrm{~d}$ passed between the first healthcare visit and screening, although 79 percent were seen within $1 \mathrm{~d}$ (median and mode values reflected same-day screening). In terms of where initial healthcare visits occurred (Table 1), those with initial visits occurring in primary care clinics had much earlier screenings (average of $9 \mathrm{~d}$ between initial visit and screen) as compared to other settings, with those first screened in inpatient settings having the longest delay (average of $128 \mathrm{~d}$ ).

On average, $44.3 \mathrm{~d}$ passed between screening and CTBIE, although 65 percent were evaluated within $30 \mathrm{~d}$ of screening $($ median $=23 \mathrm{~d}$; mode $=15 \mathrm{~d}$ ). Of the 204 individuals seen at later than $30 \mathrm{~d}$ postscreening, it was difficult in most cases to determine the reason for the delay (though 28\% were clearly the result of the patient not being able to attend the scheduled appointment). Table 3 delineates the documented follow-up attempts made by staff to get patients in for the CTBIE following positive screens for those not seen within $30 \mathrm{~d}$. For the 204 Veterans with more than $30 \mathrm{~d}$ between the TBI screen and CTBIE, the majority of contacts were made by phone (358), although certified letters were also sent. Appointments were rescheduled in the majority of instances (168).

Patient characteristics were not significantly related to the likelihood of timely screening $\left(\chi^{2}=4.09, p=0.77\right)$. However, there were significant group differences for getting a timely CTBIE $\left(\chi^{2}=16.68, p<0.05\right)$. Completing the CTBIE more than $30 \mathrm{~d}$ beyond the TBI screen was 1.8 times more likely in racial minority relative to white patients (odds ratio $=1.85,95 \%$ confidence interval $=$ 1.2-2.9). In particular, Hispanic patients were 1.5 times

Table 3.

Follow-up actions documented for 204 Veterans with $>30$ d between traumatic brain injury screen and Comprehensive Traumatic Brain Injury Evaluation.

\begin{tabular}{lc}
\hline \multicolumn{1}{c}{ Action } & Frequency \\
\hline Phone Call Attempts & 358 \\
Certified Letters Sent & 45 \\
Appointments Rescheduled & 168 \\
Rescheduled After Patient Cancelled & 87 \\
Rescheduled After No-Show & 47 \\
Rescheduled After Cancellation by Clinic & 34 \\
Note: Numbers do not add up to 204 because more than one action per patient \\
was possible.
\end{tabular}


more likely to be seen beyond $30 \mathrm{~d}$ versus within $30 \mathrm{~d}$. No other patient characteristics were associated with having an evaluation within $30 \mathrm{~d}$.

\section{Provider and Level of Care Characteristics and Timeliness}

Characteristics of the facilities that participants visited are presented in Table 1. Most initial healthcare visits occurred in primary care $(57.1 \%)$. Most participants were screened and evaluated at a polytrauma point-ofcontact (20\%) site, though there were significant missing data. Teams performed CTBIEs (52.1\%) about as often as individuals did (47.9\%). Most screens (both team and individual) were completed by nurses (35.5\%). Of those completed by one individual, the vast majority were completed by physicians $(85.4 \%)$.

Neither the polytrauma facility level nor the professional group doing the screen was significantly related to the likelihood of TBI screening within $1 \mathrm{~d}\left(\chi^{2}=0.52, p=\right.$ 0.77). Likewise, neither polytrauma facility level nor team versus individual approach to CTBIE was significantly related to the likelihood of CTBIE completion within $30 \mathrm{~d}\left(\chi^{2}=2.47, p=0.29\right)$.

\section{Assessments, Follow-up Diagnoses, Referrals, and Treatments}

The NSI was completed in all but seven $(1.1 \%)$ CTBIEs. Table 4 presents the other assessments documented during the CTBIE. Use of aspirin or analgesics (91.2\%) and review of medications (90.4\%) were frequently documented during the CTBIE, as were review of alcohol and illicit drug use (79.3\%) and tobacco use (76.4\%). Discussion of psychological issues was less frequently documented.

Table 5 details the diagnoses and problems listed in a patient's "problem list" in the medical record vis-à-vis the timing of the TBI screen and CTBIE. As shown in the table, a fair number of new problems and diagnoses were added after the TBI screen and evaluation process.

Table 6 details the healthcare services and treatment that occurred during or as a result of the CTBIE for particular symptoms. The vast majority of patients endorsing affective symptoms $(97 \%$ of the sample endorsed affective symptoms) on the NSI had those symptoms addressed during the CTBIE (79\%). Having a symptom addressed during the CTBIE meant that the provider acknowledged the problem/symptom/complaint (and documented it) and either did something about it (treatment, consult,

Table 4.

Key assessments performed during Comprehensive Traumatic Brain Injury Evaluation (CTBIE). Data presented as $n$ (\%). Numbers are rounded to add to $100 \%$.

\begin{tabular}{lccr}
\hline \multicolumn{1}{c}{ Key Assessment } & Performed & Not Performed & $\begin{array}{r}\text { Unable to Clearly } \\
\text { Determine }\end{array}$ \\
\hline Use of Aspirin and Other Analgesics & $560(91.2)$ & $45(7.3)$ & $9(1.5)$ \\
Medication Review & $555(90.4)$ & $47(7.7)$ & $12(1.9)$ \\
Alcohol or Illicit Drug Use & $487(79.3)$ & $111(18.1)$ & $16(2.6)$ \\
Tobacco Use & $469(76.4)$ & $131(21.3)$ & $14(2.3)$ \\
Fundoscopic Examination & $467(76.0)$ & $112(18.0)$ & $35(6.0)$ \\
Suicide Risk Assessment & $275(45.0)$ & $160(26.0)$ & $179(29.0)$ \\
Blood Pressure & $267(43.5)$ & $308(50.0)$ & $39(6.5)$ \\
Musculoskeletal Examination of Neck & $242(39.4)$ & $299(48.7)$ & $73(11.9)$ \\
Review of Job/School Performance & $220(35.8)$ & $226(36.8)$ & $168(27.4)$ \\
Caffeine Use & $176(28.7)$ & $411(67.0)$ & $27(4.3)$ \\
Review of Sleep Hygiene & $157(25.6)$ & $336(54.7)$ & $121(19.7)$ \\
Otological Examination & $137(22.3)$ & $444(72.3)$ & $33(5.4)$ \\
Anxiety Assessment & $126(20.5)$ & $473(77.0)$ & $15(2.5)$ \\
Depression Assessment & $82(13.3)$ & $518(84.4)$ & $14(2.3)$ \\
\hline
\end{tabular}

Note: An assessment was considered "performed" only if it was clearly performed during the CTBIE or prior to CTBIE but referenced in CTBIE. If it was clearly not performed (for example, a physical examination was conducted but there is no mention of blood pressure), it was coded as "Not Performed." An assessment was "Unable to Clearly Determine" if there was mention of this examination somewhere in the medical record but no reference or connection to it in CTBIE (e.g., the patient had a physical examination the day before the CTBIE but there is no mention of it in CTBIE report). 
Table 5.

Timing of diagnoses (Dx)/problems vis-à-vis the traumatic brain injury (TBI) screening and evaluation process $(N=614)$.

\begin{tabular}{|c|c|c|c|c|c|}
\hline Dx/Problem & $n(\%)$ & $\begin{array}{c}\text { Identified in } \\
\text { Medical Record } \\
\text { Before TBI Screen } \\
(\%)\end{array}$ & $\begin{array}{l}\text { Added Between } \\
\text { TBI Screen and } \\
\text { CTBIE (\%) }\end{array}$ & $\begin{array}{l}\text { Added After } \\
\text { CTBIE (\%) }\end{array}$ & $\begin{array}{c}\text { Additional Added } \\
\text { After TBI Screen } \\
\text { and Evaluation } \\
(\%)\end{array}$ \\
\hline$\overline{\mathrm{TBI}}$ & $230(37.5)$ & 29 & 13 & 58 & 71 \\
\hline Headaches & $271(44.1)$ & 38 & 18 & 44 & 62 \\
\hline Tinnitus & $156(25.4)$ & 48 & 22 & 30 & 52 \\
\hline Musculoskeletal Pain & $460(74.9)$ & 67 & 16 & 17 & 33 \\
\hline Other Pain & $443(72.1)$ & 70 & 15 & 15 & 30 \\
\hline Burns & $6(1.0)$ & 50 & 33 & 17 & 50 \\
\hline Amputation & $1(0.2)$ & 100 & 0 & 0 & 0 \\
\hline PTSD & $359(58.5)$ & 47 & 16 & 37 & 53 \\
\hline Relationship Difficulties & $68(11.2)$ & 74 & 1 & 25 & 26 \\
\hline Substance Abuse & $200(32.6)$ & 55 & 12 & 33 & 45 \\
\hline Mental Health NOS & $247(40.2)$ & 65 & 9 & 26 & 35 \\
\hline Other & $64(10.4)$ & 47 & 9 & 44 & 53 \\
\hline
\end{tabular}

education, etc.), offered to do something about it, or documented that something was being done about it (e.g., patient in treatment already). Of those patients referred for treatment, over half (58\%) had at least one visit. If not referred, it was typically because they were already involved in mental health treatment (91\%).

Table 6 also details the healthcare services and treatment that occurred during or as a result of the CTBIE for hearing symptoms. Eighty-nine percent of patients endorsed hearing symptoms and half (50\%) had those symptoms addressed during the CTBIE. Of those referred for treatment, over half (64\%) had at least one visit. If not referred, it was usually because they were already involved in treatment $(67 \%)$.

Finally, cognitive symptoms were endorsed by 95 percent of the study cohort. Twenty-eight percent of the patients endorsing cognitive symptoms saw a neuropsychologist, neurologist, or speech pathologist. Of those referred for treatment ( $75 \%$ of that $28 \%)$, most $(65 \%)$ had at least one visit. Of the 44 that were not referred (25\%), it was usually because they had those symptoms addressed during the CTBIE (49\%).

\section{DISCUSSION}

On average, 79 percent of patients in this national sample of positive TBI screens were screened within $1 \mathrm{~d}$ and 65 percent completed a CTBIE within $30 \mathrm{~d}$ of screening for the period between October 1, 2008, and March 31, 2011. While other investigators have examined factors associated with the likelihood of being screened and evaluated [22-23,31], few have examined timeliness. Sayer et al. [23], in their sample drawn from the inception of the TBI screening program (i.e., April 2007 to October 2008), examined factors associated with having a TBI specialty appointment within $60 \mathrm{~d}$ of screening and found that those who were Active Duty were more likely to have a follow-up appointment within 6 mo of screening, as were those who were screened at a medical center as opposed to an outpatient facility.

In our study, patient characteristics were not significantly related to the likelihood of timely screening. As might be expected, those first seen in primary care clinics tended to be screened sooner. As primary care clinics are often the first stop for many patients, screening may be most efficiently achieved there.

However, there were significant group differences for getting a timely CTBIE. Completing the CTBIE more 
JRRD, Volume 53, Number 6, 2016

Table 6.

Affective target group Comprehensive Traumatic Brain Injury Evaluation-related treatment.

\begin{tabular}{|c|c|}
\hline Patient Target Group & $n / N(\%)$ \\
\hline Affective Target Group & $594 / 614(97)$ \\
\hline Affective Specialist Related Healthcare Event & $470 / 594(79)$ \\
\hline Veterans with an Affective Specialist Referral & $272 / 470(58)$ \\
\hline With Treatment & $89 / 157(57)$ \\
\hline Did Not Have Visit & $115 / 272(42)$ \\
\hline Veterans with No Affective Specialist Referral & $198 / 470(42)$ \\
\hline Deferred Because of Established Treatment & $181 / 198(91)$ \\
\hline Veteran Had Care as Part of Comprehensive Evaluation & $18 / 198(9)$ \\
\hline Unknown & 22/198 (11) \\
\hline Administratively Closed & $4 / 198(2)$ \\
\hline With Treatment & $106 / 145(73)$ \\
\hline Did Not Have Visit & $80 / 225(35)$ \\
\hline No-Shows/Follow-Through & $56 / 80(70)$ \\
\hline Veterans Declined & $25 / 80(31)$ \\
\hline Veterans with No Hearing Specialist Referral & $48 / 273(17)$ \\
\hline Deferred Because of Established Treatment & $32 / 48(67)$ \\
\hline Veteran Had Care as Part of Comprehensive Evaluation & $4 / 48(8)$ \\
\hline Unknown & $11 / 48(23)$ \\
\hline Administratively Closed & $2 / 48(4)$ \\
\hline Cognitive Target Group & $586 / 614(95)$ \\
\hline Veterans with No Cognitive Specialist Referral & $44 / 278(25)$ \\
\hline Deferred Because of Established Treatment & $7 / 44(12)$ \\
\hline Veteran Had Care as Part of Comprehensive Evaluation & $22 / 44(49)$ \\
\hline Unknown & $17 / 44(41)$ \\
\hline
\end{tabular}

Note: Veterans can have multiple healthcare visits. For example, although 115 in the affective domain did not have a visit, the reasons for that (no shows or declined) may have been recorded multiple times on the same patient. Percentages are rounded to the nearest whole number.

than $30 \mathrm{~d}$ beyond the TBI screen was more likely in racial minority than white patients. It is unclear why this would be the case, although other variables not examined in this study may be a factor, such as geographic distance from the evaluation site. We were unable to fully explore these other potential factors. Because participants were nested within facility and in turn level of care, this analysis was necessarily confounded and will need to be further explored. Therefore, no conclusions can reasonably be drawn about race because other factors related to particular facilities may have driven the finding. Facility characteristics (such as polytrauma facility level, the professional group doing the screen, and whether a team vs an individual completed the CTBIE) were not significantly related to the 
timeliness of either the screen or the CTBIE. Timeliness, at least during the study period, was not related to which professional discipline conducted the screen or evaluation, a team versus individual approach, or the level of polytrauma facility. However, there were considerable missing data on facility, suggesting the need for further study. The lack of significant relationship of certain practice variations, for example, the team versus individual approach, to timeliness suggests that individual facilities may wish to choose the more cost-efficient practice. However, it is important to note that quality was not examined in this study. That is, it may be that one approach versus another results in a better quality CTBIE. As a first step in standardizing the CTBIE, Vanderploeg et al. used a six-step process to develop a semistructured interview for use across providers [32]. An expert panel recommended future manual development to train clinicians to use the newly developed protocol that contains both closed-end and confirmatory questions.

Of the patients who had the CTBIE beyond the $30 \mathrm{~d}$ window, the efforts documented to reach those patients were considerable and suggest that patient (rather than provider) factors likely created the delay. Multiple phone calls, letters, and rescheduling attempts were well documented.

Medical assessments (e.g., review of medication use and substance use and abuse) were the main activities documented beyond TBI-specific procedures. Psychological issues were less frequently documented in free text; however, for those patients who endorsed psychological symptoms on the NSI (such as feeling anxious or depressed), the majority had those symptoms addressed during the CTBIE. Of those referred for treatment, over half $(58 \%)$ had at least one visit. If not referred, it was usually because they were already involved in mental health treatment $(91 \%)$. It should be noted that the TBI screen is administered concurrently with other postdeployment screens, including mental health screens. As such, these patients may have already been in treatment as a result of those screens, thus reflecting the multiple comorbidities with overlapping symptoms, such as posttraumatic stress disorder and depression, often experienced by Veterans with TBI [33].

Fewer patients had either hearing complaints (50\%) or cognitive complaints (47\%) addressed via CTBIE. However, of those referred for treatment for hearing issues, over half (64\%) had at least one specialty visit related to hearing, and of those not referred, 67 percent had already been engaged in treatment. For cognitive issues, 84 percent were referred on to a specialist, with 70 percent having at least one visit.

These data must be interpreted in light of the fact that most patients (with many comorbidities) endorsed multiple overlapping symptoms, and it is quite likely that the CTBIE and subsequent referral(s) focused on the primary complaint(s) rather than all endorsed symptoms. For this study, the focus was on predefined symptom clusters rather than individual symptoms. This was done in an attempt to examine compliance with the VHA's algorithm of suggested treatments and follow-up in light of certain symptom complaints. However, in reality, the CTBIE clinician's decisions were likely most affected by the patient's primary complaint, something that was not investigated here. In addition, there was a high rate of symptom endorsement overall, with the average NSI score of about 36, suggesting that symptoms were endorsed on average at the moderate level. With endorsement that high, addressing each individual symptom becomes quite difficult. Finally, based on the individualized CTBIE and clinical decision, there might be various reasons why new referrals or consults may not be generated solely on patient's reported symptoms. The patients may have had prior evaluation and treatment, declined further evaluation, or already had effective compensatory strategies and skills to minimize functional effect on their daily living activities. Indeed, data suggest that most patients not referred for follow-up for particular symptoms had either already been in treatment or had the symptom addressed via CTBIE (e.g., education, treatment). Future study is needed to examine the quality or effectiveness of those treatments and to determine whether symptoms resolve over time.

Examination of Table 5 suggests that a significant number of new problems and diagnoses were added to the medical record after the TBI screen and evaluation process, as was the initial intent of this system. That is, the CTBIE was designed to offer a treatment plan for symptoms and problems, regardless of TBI status. Not surprisingly, TBI and related issues (e.g., cognitive disorders, headaches) were the most frequently added diagnoses following the TBI screening and evaluation process. The increased recognition of non-TBI-related diagnoses and problems, especially the high percentage of musculoskeletal pain and other pain, emphasizes the comprehensive nature of the VA's postdeployment screening. 


\section{CONCLUSIONS}

In conclusion, data from our study provide evidence that the VHA has responded to the problem of TBI in Veterans through screening, evaluation, and facilitating access to care that reaches beyond TBI and includes identification of and treatment for problems associated or unassociated with affective, cognitive, and hearing symptoms. This study found that evaluations were done consistently across the entire system of care. Facility and participant characteristics were generally not associated with timeliness. The vast majority of patients were screened within $1 \mathrm{~d}$ and comprehensively evaluated within $30 \mathrm{~d}$ of screening. The screening and evaluation process resulted in increased recognition of non-TBIrelated diagnoses and problems, especially musculoskeletal pain and other pain, emphasizing the comprehensive nature of the VA's postdeployment screening. In cases where patients were not screened or evaluated within the expected timeframes, documentation suggested multiple reasons for delays and multiple attempts to contact Veterans through phone calls and letters. The major limitation of the study was related to the use of data from the electronic medical record; we were limited to what was charted by providers. Inferences were necessarily made with respect to specific treatments and referrals as they related to specific symptoms (e.g., it was unclear whether "cognitive referrals" actually addressed cognitive symptoms). Given the overlapping nature of symptoms in this cohort, symptom prioritization or triaging was likely the standard practice.

\section{ACKNOWLEDGMENTS}

\author{
Author Contributions: \\ Study concept and design: H. G. Belanger, G. Powell-Cope. \\ Acquisition of data: H. G. Belanger, G. Powell-Cope, A. M. Spehar, \\ M. McCranie, S. A. Klanchar, R. Yoash-Gantz, J. B. Kosasih, \\ J. Scholten. \\ Analysis and interpretation of data: H. G. Belanger, G. Powell-Cope, \\ A. M. Spehar, M. McCranie, S. A. Klanchar, R. Yoash-Gantz, \\ J. B. Kosasih, J. Scholten. \\ Drafting of manuscript: H. G. Belanger, G. Powell-Cope, \\ A. M. Spehar, M. McCranie, S. A. Klanchar, R. Yoash-Gantz, \\ J. B. Kosasih, J. Scholten. \\ Critical revision of manuscript for important intellectual content: \\ G. Powell-Cope, H. G. Belanger. \\ Statistical analysis: H. G. Belanger, M. McCranie. \\ Obtained funding: G. Powell-Cope, H. G. Belanger. \\ Administrative, technical, or material support: A. M. Spehar.
}

Study supervision: G. Powell-Cope, H. G. Belanger.

Financial Disclosures: The authors have declared that no competing interests exist.

Funding/Support: This material was based on work supported by the VA Health Services Research and Development (award IAC 08-101) and the Defense and Veterans Brain Injury Center. Further support was provided by the James A. Haley Veterans' Hospital.

Additional Contributions: We would like to thank our many collaborators at multiple VA sites across the country who contributed to this project. The local site investigators were Kerry Donnelly (Buffalo, NY), Denise Kresevic (Cleveland, OH), Cheryl Johnston (Columbus, $\mathrm{OH}$ ), Lisa Brenner (Denver, CO), Norifusa Anegawa (Honolulu, HI), Steve Herman (Indianapolis, IN), Patty Jackson (Lexington, KY), Mary Marchetto (Manchester, NH), Judith Kosasih (Milwaukee, WI), Kelly Petska and Rose C. Collins (Minneapolis, MN), Sheila M. Baer (Captain James A. Lovell Federal Health Care Center [formerly North Chicago], IL), Odette Harris and John Poole (Palo Alto, CA), Dana Epstein (Phoenix, AZ), Steve Correia (Providence, RI), Thomas Campbell (Richmond, VA), Brian Shenal (Salem, VA), Ruth YoashGantz (Salisbury, NC), Patrick Miller (Salt Lake City, UT), Jill Bormann (San Diego, CA), and Joel Scholten (Washington, DC).

Institutional Review: This study's protocol was approved by the VA Central IRB and by each individual site's local VA RDC. Approval was given by the VA Central IRB and each VA facility's RDC for waiver of informed consent for data obtained from administrative data and chart reviews.

Participant Follow-Up: The authors have no plans to notify the study subjects of the publication of this article.

\section{REFERENCES}

1. Buchan H. Gaps between best evidence and practice: Causes for concern. Med J Aust. 2004;180(6 Suppl):S48-9. [PMID:15012579]

2. McGlynn EA, Asch SM, Adams J, Keesey J, Hicks J, DeCristofaro A, Kerr EA. The quality of health care delivered to adults in the United States. N Engl J Med. 2003; 348(26):2635-45. [PMID:12826639]

http://dx.doi.org/10.1056/NEJMsa022615

3. Evensen AE, Sanson-Fisher R, D'Este C, Fitzgerald M. Trends in publications regarding evidence-practice gaps: A literature review. Implement Sci. 2010;5:11.

[PMID:20181079]

http://dx.doi.org/10.1186/1748-5908-5-11

4. Weinstein MC, Skinner JA. Comparative effectiveness and health care spending-Implications for reform. N Engl J Med. 2010;362(5):460-5. [PMID:20054039] http://dx.doi.org/10.1056/NEJMsb0911104

5. Wennberg JE. Variations in medical practice and hospital costs. Conn Med. 1985;49(7):444-53. [PMID:3928244]

6. Wennberg JE. Unwarranted variations in healthcare delivery: Implications for academic medical centres. BMJ. 2002; 
325(7370):961-4. [PMID:12399352]

http://dx.doi.org/10.1136/bmj.325.7370.961

7. Djulbegovic B, Hamm RM, Mayrhofer T, Hozo I, Van den Ende J. Rationality, practice variation and person-centred health policy: A threshold hypothesis. J Eval Clin Pract. 2015;21(6):1121-4. [PMID:26639018] http://dx.doi.org/10.1111/jep.12486

8. Djulbegovic B, van den Ende J, Hamm RM, Mayrhofer T, Hozo I, Pauker SG; International Threshold Working Group (ITWG). When is rational to order a diagnostic test, or prescribe treatment: The threshold model as an explanation of practice variation. Eur J Clin Invest. 2015;45(5): 485-93. [PMID:25675907] http://dx.doi.org/10.1111/eci.12421

9. Belanger HG, Uomoto JM, Vanderploeg RD; Veterans Health Administration. The Veterans Health Administration's (VHA's) Polytrauma System of Care for mild traumatic brain injury: Costs, benefits, and controversies. J Head Trauma Rehabil. 2009;24(1):4-13. [PMID:19158591] http://dx.doi.org/10.1097/HTR.0b013e3181957032

10. Sigford BJ. "To care for him who shall have borne the battle and for his widow and his orphan" (Abraham Lincoln): The Department of Veterans Affairs polytrauma system of care. Arch Phys Med Rehabil. 2008;89(1):160-2.

[PMID:18164348] http://dx.doi.org/10.1016/j.apmr.2007.09.015

11. Marshall KR, Holland SL, Meyer KS, Martin EM, Wilmore M, Grimes JB. Mild traumatic brain injury screening, diagnosis, and treatment. Mil Med. 2012;177(8S):67-75. [PMID:22953443] http://dx.doi.org/10.7205/MILMED-D-12-00110

12. Terrio H, Brenner LA, Ivins BJ, Cho JM, Helmick K, Schwab K, Scally K, Bretthauer R, Warden D. Traumatic brain injury screening: Preliminary findings in a US Army Brigade Combat Team. J Head Trauma Rehabil. 2009; 24(1):14-23. [PMID:19158592] http://dx.doi.org/10.1097/HTR.0b013e31819581d8

13. Screening and evaluation of possible traumatic brain injury in Operation Enduring Freedom (OEF) and Operation Iraqi Freedom (OIF) Veterans (VHA Directive 2010-2012) [Internet]. Washington (DC): Department of Veterans Affairs; 2010 [cited 2016 Jan 15]. Available from:

http://wwwl.va.gov/vhapublications/ViewPublication.asp?pub ID $=2176$

14. Lew HL, Otis JD, Tun C, Kerns RD, Clark ME, Cifu DX. Prevalence of chronic pain, posttraumatic stress disorder, and persistent postconcussive symptoms in OIF/OEF veterans: Polytrauma clinical triad. J Rehabil Res Dev. 2009;46(6):697-702. [PMID:20104399] http://dx.doi.org/10.1682/JRRD.2009.01.0006

15. Regasa LE, Thomas DM, Gill RS, Marion DW, Ivins BJ. Military deployment may increase the risk for traumatic brain injury following deployment. J Head Trauma Rehabil. 2016;31(1):E28-35. [PMID:26098261]

http://dx.doi.org/10.1097/HTR.0000000000000155

16. Cicerone K, Kalmar K. Persistent post-concussive syndrome: Structure of subjective complaints after mild traumatic brain injury. J Head Trauma Rehabil. 1995;10:1-17. http://dx.doi.org/10.1097/00001199-199510030-00002

17. Neurobehavioral Symptom Inventory flow sheet [Internet]. Washington (DC): Veterans Health Administration; 2007 [cited 2007 Mar 30]. Available from:

http://vaww.rehab.va.gov/docs/NSBI_flowsheet_ext.txt.

18. Scholten JD, Sayer NA, Vanderploeg RD, Bidelspach DE, Cifu DX. Analysis of US Veterans Health Administration comprehensive evaluations for traumatic brain injury in Operation Enduring Freedom and Operation Iraqi Freedom Veterans. Brain Inj. 2012;26(10):1177-84.

[PMID:22646489]

http://dx.doi.org/10.3109/02699052.2012.661914

19. Belanger HG, Vanderploeg RD, Soble JR, Richardson M, Groer S. Validity of the Veterans Health Administration's traumatic brain injury screen. Arch Phys Med Rehabil. 2012;93(7):1234-9. [PMID:22426242]

http://dx.doi.org/10.1016/j.apmr.2012.03.003

20. Vanderploeg RD, Belanger HG. Stability and validity of the Veterans Health Administration's Traumatic Brain Injury Clinical Reminder Screen. J Head Trauma Rehabil. 2015; 30(5):E29-39. [PMID:25310297] http://dx.doi.org/10.1097/HTR.0000000000000095

21. Belanger HG, Vanderploeg RD, Sayer N. Screening for remote history of mild traumatic brain injury in VHA: A critical literature review. J Head Trauma Rehabil. 2016; 31(3):204-14. [PMID:26394295] http://dx.doi.org/10.1097/HTR.0000000000000168

22. Evans CT, St Andre JR, Pape TL, Steiner ML, Stroupe KT, Hogan TP, Weaver FM, Smith BM. An evaluation of the Veterans Affairs traumatic brain injury screening process among Operation Enduring Freedom and/or Operation Iraqi Freedom veterans. PM R. 2013;5(3):210-20, quiz 220. [PMID:23375630]

http://dx.doi.org/10.1016/j.pmrj.2012.12.004

23. Sayer NA, Nelson D, Nugent S. Evaluation of the Veterans Health Administration traumatic brain injury screening program in the upper Midwest. J Head Trauma Rehabil. 2011;26(6):454-67. [PMID:22094545] http://dx.doi.org/10.1097/HTR.0b013e3181ff393c

24. Stroupe KT, Smith BM, Hogan TP, St Andre JR, Pape T, Steiner ML, Proescher E, Huo Z, Evans CT. Healthcare utilization and costs of Veterans screened and assessed for traumatic brain injury. J Rehabil Res Dev. 2013;50(8): 1047-68. [PMID:24458891] http://dx.doi.org/10.1682/JRRD.2012.06.0107 
25. McBride D, Brüggenjürgen B, Roll S, Willich SN. Anticoagulation treatment for the reduction of stroke in atrial fibrillation: A cohort study to examine the gap between guidelines and routine medical practice. J Thromb Thrombolysis. 2007;24(1):65-72. [PMID:17260164] http://dx.doi.org/10.1007/s11239-006-0002-8

26. Vikman S, Airaksinen KE, Peuhkurinen K, Tierala I, Majamaa-Voltti K, Niemelä M, Niemelä K. Gap between guidelines and management of patients with acute coronary syndrome without persistent ST elevation: Finnish prospective follow-up survey. Scand Cardiovasc J. 2003; 37(4):187-92. [PMID:12944205] http://dx.doi.org/10.1080/14017430310014919

27. Fritz JM, Cleland JA, Brennan GP. Does adherence to the guideline recommendation for active treatments improve the quality of care for patients with acute low back pain delivered by physical therapists? Med Care. 2007;45(10): 973-80. [PMID:17890995] http://dx.doi.org/10.1097/MLR.0b013e318070c6cd

28. Hepner KA, Rowe M, Rost K, Hickey SC, Sherbourne CD, Ford DE, Meredith LS, Rubenstein LV. The effect of adherence to practice guidelines on depression outcomes. Ann Intern Med. 2007;147(5):320-9. [PMID:17785487] http://dx.doi.org/10.7326/0003-4819-147-5-200709040$\underline{00007}$

29. Benge JF, Pastorek NJ, Thornton GM. Postconcussive symptoms in OEF-OIF veterans: Factor structure and impact of posttraumatic stress. Rehabil Psychol. 2009; 54(3):270-8. [PMID:19702425]

http://dx.doi.org/10.1037/a0016736

30. Hoge CW, McGurk D, Thomas JL, Cox AL, Engel CC, Castro CA. Mild traumatic brain injury in U.S. soldiers returning from Iraq. N Engl J Med. 2008;358(5):453-63. [PMID:18234750] http://dx.doi.org/10.1056/NEJMoa072972

31. Maguen S, Lau KM, Madden E, Seal K. Factors associated with completing comprehensive traumatic brain injury evaluation. Mil Med. 2012;177(7):797-803.

[PMID:22808886]

http://dx.doi.org/10.7205/MILMED-D-11-00412

32. Vanderploeg RD, Groer S, Belanger HG. Initial developmental process of a VA semistructured clinical interview for TBI identification. J Rehabil Res Dev. 2012;49(4):545-56. [PMID:22773258] http://dx.doi.org/10.1682/JRRD.2011.04.0069

33. Wilk JE, Herrell RK, Wynn GH, Riviere LA, Hoge CW. Mild traumatic brain injury (concussion), posttraumatic stress disorder, and depression in U.S. soldiers involved in combat deployments: Association with postdeployment symptoms. Psychosom Med. 2012;74(3):249-57. [PMID:22366583] http://dx.doi.org/10.1097/PSY.0b013e318244c604

Submitted for publication September 28, 2015. Accepted in revised form April 13, 2016.

This article and any supplementary material should be cited as follows:

Belanger HG, Powell-Cope G, Spehar AM, McCranie M, Klanchar SA, Yoash-Gantz R, Kosasih JB, Scholten J. The Veterans Health Administration's traumatic brain injury screen and evaluation: Practice patterns. J Rehabil Res Dev. 2016;53(6):767-80. http://dx.doi.org/10.1682/JRRD.2015.09.0187

ORCID: Gail Powell-Cope, PhD, ARNP, FAAN: 00000002-4608-0128

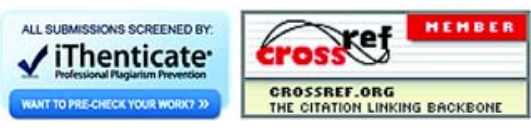

